\title{
Urinary Steroid Profile in Ironman Triathletes
}

\author{
by \\ Marta Marcos-Serrano ${ }^{1}$, Guillermo Olcina ${ }^{1}$, Carmen Crespo², Darrell Brooks ${ }^{3}$, \\ Rafael Timon ${ }^{1}$
}

The aim of this study was to determine variations in the urinary steroid profile of triathletes following an Ironman event. A total of 10 male participants (age $=36.0 \pm 1.27$ years; body height $=179.29 \pm 10.77 \mathrm{~cm}$; body mass $=$ $74.50 \pm 1.04 \mathrm{~kg}$ ) completed an Ironman Championship. Urine samples were collected before, immediately after, and 24 hours following the race. Gas chromatography-mass spectrometry (GC/MS) was used to detect and quantify catabolic and anabolic hormones: Androsterone, Dehydroepiandrosteone (DHEA), Androstenedione and Testosterone (T), Betaestradiol, Estrone, Progesterone, Cortisol (C), Cortisone, Tetrahydrocortisol (THE) and Tetrahydrocortisone (THF). These were measured in their glucuroconjugated and free forms. Androsterone (3297.80 \pm 756.83 vs. $2154.26 \pm$ 1375.38), DHEA (47.80 \pm 19.21 vs. $32.62 \pm 15.96)$ and Beta-estradiol (59.36 \pm 11.7 vs. $41.67 \pm 10.59)$ levels decreased after the event. The significant decrease of DHEA (47.80 \pm 19.21 vs. $32.11 \pm 14.03)$ remained at 24 hours. Cortisol (200.38 \pm 56.60 vs. $257.10 \pm 74.00)$ and THE ( $238.65 \pm 81.55$ vs. $289.62 \pm 77.13)$ increased after exercise and remained elevated 24 hours later (200.38 \pm 56.60 vs. $252.48 \pm 62.09$; $238.65 \pm 81.55$ vs. $284.20 \pm 66.66)$. The following anabolic/catabolic ratios fell after exercise: T/C (0.85 \pm 0.54 vs. $0.54 \pm 0.29)$, T/THE $(0.66 \pm 0.29$ vs. $0.40 \pm 0.08)$, T/THE+THF (0.38 \pm 0.17 vs. $0.24 \pm 0.06)$, DHEA/THE (0.22 \pm 0.05 vs. $0.12 \pm 0.05)$, DHEA/THF $(0.34 \pm 0.02$ vs. $0.21 \pm 0.01)$ and DHEA/THE + THF $(0.12 \pm 0.02$ vs. $0.08 \pm 0.03)$. The steroid profile showed that athletes were fatigued after finishing the competition and a catabolic state remained 24 hours later.

Key words: triathlon, steroids, urine, gas chromatography-mass spectrometry.

\section{Introduction}

The Ironman Triathlon is an extreme sport event compared to other traditional endurance activities such as swimming, cycling or running a marathon. The first Ironman was held in 1978 in Hawaii and was considered one of the world's most challenging endurance events (Lepers, 2008). This triathlon consists of three consecutive events: swimming $(3.8 \mathrm{~km})$, cycling $(180 \mathrm{~km})$ and running $(42.2 \mathrm{~km})$. Participants need to maintain a highenergy expenditure (between 8500 and $11500 \mathrm{kcal}$ ) for a long period of time if they want to succeed (Laursen and Rhodes, 2001; Lepers et al., 2010). Depending on the skills of the triathletes, the race may last between 8 and 17 hours. Consequently, other factors such as thermal regulation, electrolyte homeostasis and energy balance are also crucial to athlete's success (Laursen and Rhodes, 2001). Despite high fluid intake, the athletes sustain an average weight loss of $2.5 \mathrm{~kg}$ and a high incidence of hyponatremia is observed during ultradistance triathlons (Speedy et al., 2000, 2001). It has been observed that body composition, type of training, years of experience, environmental conditions, and sport equipment have an important influence on performance. For example, Knechtle et al. (2010) stated that total

\footnotetext{
1 - Department of Physical Education and Sport. Sports Science Faculty. University of Extremadura. Cáceres, Spain.

2- Department of Physiology. Sports Science Faculty University of Extremadura. Cáceres, Spain.

3. School of Pharmacy \& Biomedical Sciences. University of Central Lancashire. Preston, United Kingdom.
} 
race time was related to pre-race experience and training hours per week. Moreover, results of an Ironman race showed that the athletes with a lower body mass index, lower body fat and smaller upper arm and thigh circumferences had a faster running pace (Knechtle et al., 2011).

It is widely known that intensive physical exercise causes stress, producing physiological and structural changes to keep the body's homeostatic balance. This stress causes alterations in the synthesis, metabolism, and urinary excretion of steroid hormones, and modulates the anabolic/catabolic state of athletes (TimonAndrada et al., 2007). For this reason, the study of these hormones may help evaluate physical performance of athletes (Jerjes et al., 2006; Timón et al., 2009). Endogenous steroids play an important role during physical exercise and influence the recovery period by modulating anabolic and catabolic processes (Urhausen et al., 1995). The anabolic/catabolic ratio decreased in relation to the intensity and duration of physical exercise, as well as during periods of intense training, indicating that longer races caused a greater catabolic state in the athletes (Tremblay et al., 2005). Additionally, hormonal response to exercise depends on other factors such as the type of exercise or training status of the athlete. Endurance-trained subjects displayed less pronounced changes in hormone concentrations in response to a $40-\mathrm{min}$ run at $50-55 \%$ maximal oxygen uptake compared to resistance-trained counterparts (Tremblay et al., 2004).

The steroid profile after long-duration sport events has been analysed previously. Urhausen and Kindermann (1987) conducted the first study related to the recovery period after a triathlon. Testosterone remained unchanged after the race, but decreased to its lowest value two days after the event. Cortisol increased up to 4 times right after the race and returned to baseline within four days. Lutoslawska et al. (1991) analysed the steroid profile of rowers after 19 and $42 \mathrm{~km}$ of kayak races. They observed that serum cortisol was greater when the race was longer, and that the testosterone/cortisol ratio fell after the race and returned to baseline the next day. Similarly, Karkoulias et al. (2008) studied hormonal responses after a marathon race. Serum cortisol concentrations increased, but total testosterone and free testosterone concentrations decreased after the race, returning to baseline a week later. However, hormonal responses during long distance races may be different in each runner depending on their training level (Bobbert et al., 2012).

Despite the popularity of the Ironman event, scientific contributions about this topic are limited. The research is novel as it attempts to quantify the physiological stress of this demanding sport. The aim of this study was to determine the urinary steroid profile in triathletes after performing an Ironman race and to assess their fatigue.

\section{Methods}

Participants

Volunteers from several triathlon teams were contacted by telephone and mail two weeks prior to the race. They were all informed about the study's protocol and provide written consent. The experimental group consisted of 10 trained Caucasian male athletes with at least 10 years of experience in long distance training and a minimum of 15 hours of training per week (age: $36.00 \pm 1.27$ years; body height: $179.29 \pm 10.77 \mathrm{~cm}$; body mass: $74.50 \pm 1.04 \mathrm{~kg}$; fat mass: $9.02 \pm 1.04 \%$; muscular mass: $49.41 \pm 1.27 \%$ ).

The experiment was performed during the European Ironman Championship held in Frankfurt (Germany) in 2012. All participants completed the Ironman race with times ranging from 09:08:15 (hh:mm:ss) to 11:40:10. Weather conditions during the race were as follows: average temperature: $21^{\circ} \mathrm{C}$ (range 15-27), humidity: 63\% (range 19-94), wind speed: $8 \mathrm{~km} / \mathrm{h}$, rain $1 \mathrm{~mm}$.

\section{Experimental protocol and measurements}

Body mass, height and subcutaneous fat skinfolds were measured the day before the event. A portable measuring station (Seca 220, Germany) was used to measure body mass and height. Six subcutaneous fat skinfolds (abdomen, subscapular, suprailiac, triceps, calf and thigh) were assessed on the left side of the body using a Harpenden skinfold calliper, according to the instructions of the International Society for the Advancement of Kinanthropometry (ISAK). Body composition measurements were made using the Durnin and Womersley's method (1973) and the Brozek et al.'s formula (1963). Containers to collect urine were distributed the night before the 
race and athletes provided their first urine sample the morning of the race immediately after waking up.

These samples were considered 'before the competition', taken by every participant between 4:30 and 5:30 a.m. in their hotel rooms. All volunteers and researchers were hosted in the same hotel, so participants gave the urine samples to the researchers immediately after being taken. After that, triathletes had breakfast and moved to the start race area. Athletes arrived at the start line without instructions about the pace, rehydration or feeding in an attempt to avoid any influence of this investigation on their habitual routines during the race. They were allowed to drink ad libitum during the race day and one day postrace. Since contact with the athletes was not possible until the end of the race, urine samples were taken again immediately after the triathlon in a post-race area, as well as 24 hours after the event at the participant's hotel room. All urine samples were collected in a clean, dry container with a tight lid to prevent spillage, evaporation, and contamination. Before freezing the samples ($\left.20^{\circ} \mathrm{C}\right), \mathrm{pH}$ and density were measured by reagent test strips (UriDynamics HydraTrend Hydration Monitoring Test Strips, Indianapolis, IN, USA), in order to control for the variation in the water content and to adjust the hormone concentrations according to the urine specific gravity (USG). All procedures were conducted following the manufacturer's guidelines. This data is shown in Table 2 with the analysis of the following hormones:Androsterone, Dehydroepiandrosteone (DHEA), Androstenedione and Testosterone (T), Beta-estradiol, Estrone, Progesterone, Cortisol, Cortisone, Tetrahydrocortisol (THE) and Tetrahydrocortisone (THF) in their glucuroconjugated and free forms. Androgen/Corticosteroid ratios were also studied to assess the anabolic/catabolic state after the sport event and to monitor recovery of the participants.

Androgen and Estrogen analyses were performed by gas chromatography-mass spectrometry according to Galan et al. (2001) and glucocorticosteroids analysis in accordance with Rivero-Marabé et al. (2001). In both cases, a $2 \mathrm{ml}$ aliquot of human urine was centrifuged at 3000 rpm to eliminate the solid residue, then buffered to $\mathrm{pH} 7$ with $250 \mu \mathrm{l}$ of $0.2 \mathrm{M}$ phosphate. 17- $\alpha$ - methyltestosterone internal standard solution (600 ng) was added and the sample was mixed. The hydrolysis was done with $50 \mu \mathrm{l}$ of $\beta$ glucoronidase enzyme at $50^{\circ} \mathrm{C}$ for $1 \mathrm{~h}$. After hydrolysis, $250 \mu$ of potassium carbonate buffer (7\%), pH 9-10 were added. The steroids were extracted with $2 \mathrm{ml}$ of diethyl ether for $15 \mathrm{~min}$ in a mixer at $110 \mathrm{rpm}$. The organic phase was then evaporated to dryness under a gentle nitrogen stream. Afterwards, the derivation process was performed, which differed between androgens and glucocorticosteroids. For androgens, the dry steroid residue was derivated with $50 \mu \mathrm{l}$ of $\mathrm{N}$ methyl-N-(trimethylsilyl) trifluoroacetamide (MSTFA)/NH4I/dithioerytritol (1000:2:4, v/w/w) solution at $60^{\circ} \mathrm{C}$ for $15 \mathrm{~min}$ to generate the TMS ether derivatives. A 1- $\mu$ l sample of the liquid residue was injected in split less mode. Glucocorticosteroids were derived from the dry corticosteroids residue. This was treated with 100 $\mu l$ of methoxyamine hydrochloride solution in pyridine at $60^{\circ} \mathrm{C}$ for $30 \mathrm{~min}$. After cooling, excess pyridine was evaporated under nitrogen. The residue was reconstituted with $50 \mu \mathrm{l}$ of the MSTFA-TMS imidazole $(0.2 \%)$ reagent, and the mixture reacted at $70^{\circ} \mathrm{C}$ for $50 \mathrm{~min}$ to make the MO-TMS ether derivatives. A 1- $\mu$ l volume of the liquid residue was analysed by GC-MS and MSMS modes.

Androgen and Estrogen assays were performed using an HP-5890 Series II gas chromatograph equipped with a simple quadruple HP-5972 mass spectrometer (GC/MS system, SIM mode), and a Varian 3800 gas chromatograph coupled to a Saturn 2000 massmass (ion-trap) spectrometer (GC/MS/MS system) for glucocorticosteroids.

The experiment, which was developed following the amendments of the Declaration of Helsinki, was conducted following approval from the Committee of Biomedical Ethics of the University of Extremadura.

\section{Statistical Analysis}

The statistical analysis was carried out with SPSS 19.0 computer software for Windows. The Kolmogorov-Smirnov test was applied to verify a normal distribution of data and the Levene's test was used to assess the homogeneity of variance. A repeated-measures linear model was used to compare responses in each variable over time. Post hoc comparisons were performed 
using the Bonferroni test to identify significant changes in the different time points. Means and standard deviations (SD) were used as descriptive statistics. The level of significance was set at $p \leq$ 0.05 , with a confidence level of $95 \%$. Observed power was calculated for this significance level. The effect size (Cohen's d) was calculated for all variables over time. The magnitude of the difference was considered small (0.2), moderate (0.5) or large (0.8) (Cohen, 1992).

\section{Results}

Urine characteristics are presented in Table 1. No significant difference was found in values of $\mathrm{pH}$ and urine specific gravity.

The other Tables show the concentrations of hormones and their metabolites before the event, after competition, and 24 hours after finishing the Ironman event.

Androgens, Estrogens, Progesterone and Corticosteroids excretion is shown in Table 2. Androsterone, DHEA and Beta-estradiol values decreased significantly after the event. DHEA values remained significantly lower 24 hours after the Ironman. On the other hand, Tetrahydrocortisol and Cortisol values increased after the Ironman competition and remained elevated 24 hours after the event.

Lastly, different Androgen/Corticosteroid ratios are presented in Table 3. Testosterone/Cortisol, T/THE, T/THE+THF, DHEA/THE, DHEA/THF and DHEA/THE+THF ratios decreased after the Ironman event.

\section{Table 1}

$p H$ and urine specific gravity (mean $\pm S D$ )

\begin{tabular}{lccc}
\hline Urine variables & Before & Immediately After & 24 hours \\
\hline $\mathrm{pH}$ & $6.04 \pm 0.40$ & $6.23 \pm 0.52$ & $6.09 \pm 903.82$ \\
$\mathrm{USG}\left(\mathrm{g}^{*} \mathrm{~mL}^{-1}\right)$ & $1.016 \pm 0.005$ & $1.022 \pm 0.007$ & $1.018 \pm 0.007$ \\
\hline
\end{tabular}

Table 2

Urinary excretion of androgens, estrogens, progesterone and corticosteroids (mean $\pm S D$, expressed in $n g / m l$ )

\begin{tabular}{|c|c|c|c|c|c|}
\hline Substance & Before & $\begin{array}{c}\text { Immediately } \\
\text { After }\end{array}$ & 24 hours & Size effect $(\mathrm{d})$ & $\begin{array}{c}\text { Observed } \\
\text { power }(1-\beta)\end{array}$ \\
\hline Androsterone & $\begin{array}{c}3297.80 \pm \\
756.83\end{array}$ & $\begin{array}{c}2154.26 \pm \\
1375.38^{*}\end{array}$ & $3132.92 \pm 903.82$ & 0.51 & 0.61 \\
\hline DHEA & $47.80 \pm 19.21$ & $32.62 \pm 15.96^{*}$ & $32.11 \pm 14.03^{+}$ & 0.53 & 0.67 \\
\hline Androstenedione & $39.48 \pm 21.51$ & $34.75 \pm 23.33$ & $28.85 \pm 11.32$ & 0.11 & 0.21 \\
\hline Testosterone & $161.54 \pm 104.63$ & $117.62 \pm 47.07$ & $164.61 \pm 108.64$ & 0.41 & 0.57 \\
\hline Estrone & $20.94 \pm 4.44$ & $18.30 \pm 4.27$ & $19.60 \pm 7.55$ & 0.12 & 0.21 \\
\hline Beta-Estradiol & $59.36 \pm 11.74$ & $41.67 \pm 10.59^{*}$ & $51.92 \pm 14.82$ & 0.51 & 0.76 \\
\hline Progesterone & $243.13 \pm 84.16$ & $200.67 \pm 84.22$ & $277.79 \pm 147.56$ & 0.17 & 0.25 \\
\hline Tetrahydrocortisol & $238.65 \pm 81.55$ & $289.62 \pm 77.13^{*}$ & $284.20 \pm 66.66^{+}$ & 0.56 & 0.87 \\
\hline Cortisol & $200.38 \pm 56.60$ & $257.10 \pm 74.00^{*}$ & $252.48 \pm 62.09^{+}$ & 0.56 & 0.85 \\
\hline Tetrahydrocortisone & $156.21 \pm 87.00$ & $190.82 \pm 73.56$ & $148.06 \pm 44.89$ & 0.21 & 0.29 \\
\hline Cortisone & $176.21 \pm 69.97$ & $227.50 \pm 64.85$ & $213.72 \pm 63.97$ & 0.18 & 0.22 \\
\hline
\end{tabular}




\begin{tabular}{|c|c|c|c|c|c|}
\hline \multicolumn{6}{|c|}{ Table 3} \\
\hline Relation & Before & Immediately After & 24 hours & Size effect (d) & $\begin{array}{c}\text { Observed } \\
\text { power }(1-\beta)\end{array}$ \\
\hline Testosterone/Cortisol & $0.85 \pm 0.54$ & $0.54 \pm 0.29^{*}$ & $0.75 \pm 0.64$ & 0.43 & 0.56 \\
\hline $\mathrm{T} / \mathrm{THE}$ & $0.66 \pm 0.29$ & $0.40 \pm 0.08^{*}$ & $1.06 \pm 0.84$ & 0.48 & 0.64 \\
\hline $\mathrm{T} / \mathrm{THF}$ & $1.05 \pm 0.72$ & $0.66 \pm 0.33$ & $1.29 \pm 0.90$ & 0.39 & 0.51 \\
\hline $\mathrm{T} / \mathrm{THE}+\mathrm{THF}$ & $0.38 \pm 0.17$ & $0.24 \pm 0.06^{*}$ & $0.57 \pm 0.44$ & 0.52 & 0.71 \\
\hline DHEA / THE & $0.22 \pm 0.05$ & $0.12 \pm 0.05^{*}$ & $0.18 \pm 0.09$ & 0.45 & 0.55 \\
\hline DHEA / THF & $0.34 \pm 0.02$ & $0.21 \pm 0.01^{*}$ & $0.22 \pm 0.01$ & 0.53 & 0.72 \\
\hline DHEA / THE+ THF & $0.12 \pm 0.02$ & $0.08 \pm 0.03^{*}$ & $0.10 \pm 0.04$ & 0.51 & 0.67 \\
\hline \multicolumn{6}{|c|}{${ }^{*} p<0.05$ for difference between Before and Immediately After values. } \\
\hline
\end{tabular}

\section{Discussion}

Most studies evaluating the effects of endurance exercises on steroid profiles (Testosterone and Cortisol) were performed using blood samples although some investigations have used urine samples as study specimens (Bouget et al., 2006; Maynar et al., 1994). This sample method has several advantages including being noninvasive, speed of component analysis, and easy management of sample taking (Timon et al., 2008). To our knowledge no previous study has analysed the urinary steroid profile in Ironman triathletes, although our results are very similar to other studies that analysed the urinary steroid profile of elite cyclists. One such a study observed a significant increase of urinary corticosteroids after a competitive mountain bicycle race lasting about 2.5 hours (Gatti et al., 2005) and another showed a decrease of urinary androgen hormones after training in road cyclists (Maynar et al., 1994).

With regard to Androgens, Androsterone decreased immediately after the Ironman competition, returning to baseline values 24 hours after exercise. These results are similar to those found by other authors where blood testosterone levels suffered a significant reduction of $58 \%$ after an Ironman triathlon compared to levels registered two days before the competition (Ginsburg et al., 2001), as well as a reduction of $53 \%$ in testosterone levels compared to baseline levels registered two days before the Ironman triathlon and returning to pre-race levels five days later (Neubauer et al., 2008). Additionally, blood testosterone levels dropped after a marathon race in non-elite runners compared with levels measured one week before the race and returned to baseline one week after the race (Karkoulias et al., 2008). The high workload of this sport event could cause a dysfunction in the hypothalamicpituitary axis altering testosterone produced by the testicles and decreasing the metabolites of testosterone in urine (Timon-Andrada et al., 2007). However, this fall could also be caused by a high testosterone demand required to establish an anabolic state and to deal with fatigue generated by the exercise (Cumming, 2000). Given that these athletes require a high volume of specific training, they may have adapted. Specifically, men chronically exposed to this type of training exhibit persistently reduced basal free and total testosterone concentrations without concurrent LH elevations. Men displaying these values have been deemed to exhibit the "exercise-hypogonadal male condition" (Hackney, 2008).

On the other hand, DHEA values (from adrenal origin) also decreased immediately after the competition and low concentrations were maintained 24 hours after finishing the event. Previous studies have found an important slowdown in the adrenal gland after a long period of intense training or competition as observed by Lombardi et al. (2012), with a decrease in adrenal hormones after a 3-week stage race in trained cyclists. Since DHEA values were reduced 24 hours post-race, the adrenal slowdown did not 
occur, but a performance alteration may develop. This hypothesis could be supported by the androstenedione excretion (from the adrenal gland as well) that showed a decreasing tendency, although no significant changes were found. Therefore, the adrenal gland seems to be more affected by exercise stress than the testicular gland, a conclusion supported by a previous investigation (Kuoppasalmi et al., 1980).

Urinary excretion of Beta-estradiol was reduced after the Ironman event and associated with Estrogen and Progesterone concentration. Immediately after intense exercise, high amounts of Androgens are required to deal with stress. Accordingly, the aromatization process from Testosterone to Beta-estradiol may be decreased and therefore result in a reduced urinary Betaestradiol excretion (Broeder et al., 2000).

Cortisol and Tetrahydrocortisol concentrations increased after the Ironman competition and remained high 24 hours after the event. These results are consistent with those found by Neubauer et al. (2008), who observed a significant increase of $241 \%$ in the Cortisol level after an Ironman triathlon compared to baseline values. In a similar fashion, increases in Cortisol concentrations were observed after a marathon with a greater increase in less trained participants compared to highly trained athletes (Bobbert et al., 2012). This would corroborate the hypothesis that the adrenal gland was affected by exercise stress, causing a predominantly catabolic state (Lac and Berthon, 2000).

Lastly, anabolic/catabolic ratios are biomarkers that can provide information about the stress level and the state of an athlete. Previous results have shown that Testosterone/Cortisol, T/THE, T/THE+THF, DHEA/THE, DHEA/THF and DHEA/THE+THF ratios decrease after the Ironman competition, indicating that individuals were in a catabolic state as may be expected after an extreme competition (Balthazar et al., 2012; Lac and Berthon, 2000). All ratios were reduced, acting as indicators of the increased stress level that these triathletes endured during such a demanding competition. Surprisingly, the next day all ratios had increased, showing a slight anabolic tendency. Similar results were found in a group of sub-elite athletes who participated in a six-hour race (Lac and Berthon, 2000). Previous research has suggested that exercise intensity plays a more important role than its duration in determining the magnitude of endocrine response (Kuoppasalmi et al., 1980; Tremblay et al., 2005). Considering that the triathletes participating in this study were well-trained and that the race pace was not very high, it seems that the endocrine response began to return to baseline values 24 hours after the competition.

This research study had some limitations. The small simple size of the study diminishes its power. Other biomarkers of muscle fatigue (such as $\mathrm{CK}, \mathrm{BUN}$, ammonium or total proteins) were not analysed, and could have supported the results. Moreover, the lack of plasma data makes it difficult to determine whether variations in urinary excretion of steroid hormones were the result of changes in the steroid synthesis or changes in the use of these steroids by muscles.

\section{Conclusion}

Based on the reduction of urine Androgen and increase of urine Corticosteroid concentrations, it may be concluded that the participants were in a catabolic state after the Ironman triathlon. This study aimed to observe the catabolic state in trained athletes in relation to changes in steroid concentrations, but these changes were not as significant as would have been expected after an event of this magnitude. Therefore, more than 24 hours is needed to restore the steroid hormonal balance. Moreover, these results should be taken into account when evaluating athletes recovery periods and establishing the time required before beginning intensive training sessions.

\section{Acknowledgements}

Financial support for this study was received from the Regional Government of Extremadura (Spain) (dossier number: GR15020-CTS036). 


\section{References}

Balthazar CH, García MC, Spadari-Bratfisch RC. Salivary concentrations of cortisol and testosterone and prediction of performance in professional triathlon competition. Stress, 2012; 15(5): 495-502. doi: $10.3109 / 10253890.2011 .642033$

Bobbert T, Mai K, Brechtel L, Weger B, Pfeiffer AF, Spranger J, Diederich S. Leptin and endocrine parameters in marathon runners. Int J Sports Med, 2012; 33(3): 244-8. doi: 10.1055/s-0031-1291251

Bouget M, Rouveix M, Michaux O, Pequignot JM, Filaire E. Relationships among training stress, mood and dehydroepiandrosterone sulphate/cortisol ratio in female cyclists. J Sport Sci, 2006; 24(12): 1297-1302. doi: $10.1080 / 02640410500497790$

Broeder CE, Quindry J, Brittingham K, Panton L, Thomson J, Appakondu S, Breuel K, Byrd R, Douglas J, Earnest C, Mitchell C, Olson M, Roy T, Yarlagadda C. The Andro Project: physiological and hormonal influence of androstenedione supplementation in men 35 to 65 years old participating in a high intensity resistance training program. Arch Intern Med, 2000; 160(20): 3093-3104. doi:10.1001/archinte.160.20.3093

Brozek J, Grande F, Anderson JT, Keys A. Densitometric analysis of body composition: Revision of some quantitative assumptions. Ann NY Acad Sci, 1963; 110: 113-140. doi: 0.1111/j.1749-6632.1963.tb17079.x

Cohen J. A power primer. Psychol Bull, 1992; 112, 155-159. Doi: 10.1037/0033-2909.112.1.155

Cumming DC. The male reproductive system, exercise and training. In Warren MP, Constantini NW. (Eds.) Contemporary Endocrinology: Sports Endocrinology. Totowa, NJ: Human Press, 119-132; 2000

Durnin JVGA, Womersley J. Body fat assessed from total body density and its estimation from skinfold thickness: measurements on 481 men and women aged from 16 to 72 years. Brit J Nutr, 1974; 32(1): 7797. doi: 10.1079/BJN19740060

Galán Martín AM, Maynar Mariño JI, García de Tiedra MP, Rivero Marabé JJ, Caballero Loscos MJ, Maynar Mariño M. Determination of nandrolone and metabolites in urine samples from sedentary persons and sportmen. J Chromatogr B Biomed Sci Appl, 2001; 761(2): 229-236. doi: 10.1016/S0378-4347(01)003383

Gatti R, Cappellin E, Zecchin B, Antonelli G, Spinella P, Mantero F, De Palo EF. Urinary high performance reverse phase chromatography cortisol and cortisone analyses before and at the end of a race in elite cyclists. J Chromatogr B Analyt Technol Biomed Life Sci, 2005; 824(1-2): 51-6. doi: 10.1016/j.jchromb.2005.06.037

Ginsburg GS, O'Toole M, Rimm E, Douglas PS, Rifai N. Gender differences in exercise-induced changes in sex hormone levels and lipid peroxidation in athletes participating in the Hawaii Ironman triathlon. Ginsburg-gender and exercise-induced lipid peroxidation. Clin Chim Acta, 2001; 305(1-2): 131-9. doi: $10.1016 / 50009-8981(00) 00427-7$

Hackney AC. Effects of endurance exercise on the reproductive system of men: the "exercise-hypogonadal male condition". J Endocrinol Invest, 2008; 31(10): 932-938. doi: 10.1007/BF03346444

Jerjes WK, Peters TJ, Taylor NE, Wood PJ, Wessely S, Cleare AJ. Diurnal excretion of urinary cortisol, cortisone, and cortisol metabolites in chronic fatigue syndrome. J Phychosom Res, 2006; 60(2): 145-153. doi: $10.1016 / j . j p s y c h o r e s .2005 .07 .008$

Karkoulias K, Habeos I, Charokopos N, Tsiamita M, Mazarakis A, Pouli A, Spiropoulos K. Hormonal responses to marathon running in non-elite athletes. Eur J Intern Med, 2008; 19(8): 598-601. doi: 10.1016/j.ejim.2007.06.032

Knechtle B, Wirth A, Baumann B, Knechtle P, Rosemann T. Personal Best Time, Percent Body Fat, and Training Are Differently Associated With Race Time for Male and Female Ironman Triathletes. Res $Q$ 
Exercise Sport, 2010; 81(1): 62-8. doi: 10.1080/02701367.2010.10599628

Knechtle B, Wirth A, Rüst CA, Rosemann T. The Relationship between Anthropometry and Split Performance in Recreational Male Ironman Triathletes. Asian J Sports Med, 2011; 2(1): 23-30. doi: 10.5167/uzh-49177

Kuoppasalmi K, Nasveri H, Harkonen M, Adlercreutz H. Plasma cortisol, androstenedione, testosterone and luteinizing hormone in running exercise of different intensities. Scand J Clin Lab Invest, 1980; 40(5): 4039. doi: 10.3109/00365518009101862

Lac G, Berthon P. Changes in cortisol and testosterone levels and $\mathrm{T} / \mathrm{C}$ ratio during an endurance competition and recovery. J Sport Med Phys Fit, 2000; 40(2): 139-44. doi: 10.1249/MSS.0b013e31817e91a4

Laursen PB, Rhodes EC. Factors Affecting Performance in an Ultraendurance Triathlon. Sports Med, 2001; 31(3): 195-209. doi: 10.2165/00007256-200131030-00004

Lepers R. Analysis of Hawaii Ironman Performances in Elite Triathletes from 1981 to 2007. Med Sci Sport Exer, 2008; 40(10): 1828-1834. doi: 10.1249/MSS.0b013e31817e91a4

Lepers R, Sultana F, Bernard T, Hausswirth C, Brisswalter J. Age-Related Changes in Triatlon Performances. Int J Sports Med, 2010; 31(4): 251-6. doi: 10.1055/s-0029-1243647

Lombardi G, Lanteri P, Graziani R, Colombini A, Banfi G, Corsetti R. Bone and energy metabolism parameters in professional cyclists during the Girod'Italia 3-weeks stage race. PlosOne, 2012; 7(7): e42077. doi: 10.1371/journal.pone.0042077

Lutoslawska G, Obminski Z, Kroqulski A, Sendecki W. Plasma cortisol and testosterone following 19-km and 42-km kayak races. J Sport Med Phys Fit, 1991; 31(4): 538-42

Maynar M, Caballero MJ, Mena P, Rodríguez C, Cortes R, Maynar JI. Urine excretion of androgen hormones in professional racing cyclists. Eur J Appl Physiol O, 1994; 68(3): 200-204. doi: dx.doi.org/10.1007/BF00376767

Neubauer O, König D, Wagner KH. Recovery after an Ironman triahtlon: sustained inflammatory responses and muscular stress. Eur J Appl Physiol, 2008; 104(3): 417-426. doi: 10.1007/s00421-008-0787-6

Rivero Marabé JJ, Maynar Mariño JI, García de Tiedra MP, Galán Martín AM, Caballero Loscos MJ, Maynar Mariño M. Determination of natural corticosteroids in urine samples from sportsmen. J Chromatogr $B$ Biomed Sci Appl, 2001; 761(1): 77-84. doi: 10.1016/S0378-4347(01)00306-1

Speedy DB, Rogers IR, Noakes TD, Thompson JM, Guirey J, Safih S, Boswell DR. Diagnosis and prevention of hyponatremia at an ultradistance triathlon. Clin J Sport Med 2000; 10: 52-58. doi: 10.1097/00042752200001000-00010.

Speedy DB, Noakes TD, Kimber NE, Rogers IR, Thompson JM, Boswell DR, Ross JJ, Campbell RG, Gallagher PG, Kuttner JA. Fluid balance during and after an ironman triathlon. Clin J Sport Med 2001; 11(1): 44-50. doi: 10.1097/00042752-200101000-00008

Timón Andrada R, Maynar Mariño M, Muñoz Marín D, Olcina Camacho GJ, Caballero MJ, Maynar Mariño JI. Variations in urine excretion of steroid hormones after an acute session and after a 4-week programme of strength training. Eur J Appl Physiol, 2007; 99: 65-71. doi: 10.1007/s00421-006-0319-1

Timón R, Olcina G, Tomas-Carus P, Muñoz D, Toribio F, Raimundo A, Maynar M. Urinary steroid profile after the completion of concentric and concentric/eccentric trials with the same total workload. $J$ Physiol Biochem, 2009; 65(2): 105-112. doi: 10.1007/BF03179061

Timón R, Olcina G, Muñoz D, Maynar JI, Caballero MJ, Maynar, M. Determination of urine steroid profile in untrained men to evaluate recovery after a strength training session. J Strength Cond Res, 2008; 22(4): 1087-93. doi: 10.1519/JSC.0b013e31816d4542

Tremblay MS, Copeland JL, Van Helder W. Influence of exercise duration on postexercise steroid hormone 
responses in trained males. Eur J Appl Physiol, 2005; 94(5-6): 505-513. doi: 10.1007/s00421-005-1380-x

Tremblay MS, Copeland JL, Van Helder W. Effect of training status and exercise mode on endogenous steroid hormones in men. J Appl Physiol, 2004; 96(2): 531-539. doi: 10.1152/japplphysiol.00656.2003

Urhausen A, Gabriel H, Kindermann W. Blood hormones as markers of training stress and overtraining. Sports Med, 1995; 20(4): 251-276. doi: 10.2165/00007256-199520040-00004

Urhausen A, Kindermann W. Behaviour of testosterone, sex hormone binding globulin (SHBG), and cortisol before and after a triathlon competition. Int J Sports Med, 1987; 8(5): 305-8. doi: 10.1055/s-2008-1025674

\section{Corresponding author:}

\section{Marta Marcos-Serrano}

Sports Science Faculty. University of Extremadura.

Avenida de la Universidad s/n (10003) Cáceres, Spain.

Phone number: +34927257460

Fax number: +34 927257461

E-mail: mmarcosserrano@gmail.com 